\title{
Treatment Strategies for Atopic Dermatitis: Optimizing the Available Therapeutic Options
}

\author{
Amy S. Paller, MD, ${ }^{\dagger}$ Eric L. Simpson, MD, MCR, ${ }^{\ddagger}$ Lawrence F. Eichenfield, MD, ${ }^{\S}$ \\ Charles N. Ellis, MD," and Anthony J. Mancini, MD"
}

\begin{abstract}
Bathing and moisturization to control dryness, applications of topical anti-inflammatory agents (including corticosteroids and calcineurin inhibitors [TCls]) to control flares, minimization of the risk for infection, and relief of pruritus are the cornerstones of effective therapy for atopic dermatitis. Education of parents and patients is crucial to enhance adherence. Strategies for reduced Staphylococcus aureus colonization may help control re-emergence of flares following cessation of antimicrobial treatment for infection; these include dilute bleach baths and minimizing the risk for contamination of topical agents. In severe, refractory cases, more aggressive therapy with systemic immunosuppressants may be considered, but appropriate laboratory testing must be included as part of patient monitoring during treatment. The value of adjuvant therapy with wet wraps to "cool down" particularly erythematous and pruritic flares is becoming increasingly recognized.
\end{abstract}

Semin Cutan Med Surg 31(suppl 3):S10-S17 @ 2012 Elsevier Inc. All rights reserved.

KEYWORDS atopic dermatitis treatment, bleach baths, Staphylococcus aureus colonization

†Walter J. Hamlin Professor and Chair, Department of Dermatology, Professor of Pediatrics, Northwestern University Feinberg School of Medicine, Attending Physician, Ann \& Robert Lurie Children's Hospital of Chicago, Chicago, IL

¥Associate Professor of Dermatology and Director of Clinical Studies, Oregon Health and Science University, Portland, OR.

§Professor of Clinical Pediatrics and Medicine (Dermatology) Chief, Pediatric and Adolescent Dermatology, University of California, San Diego School of Medicine, Rady Children's Hospital, San Diego, CA.

\|William B. Taylor Professor of Clinical Dermatology, Associate Chair, Department of Dermatology, University of Michigan Medical Center, Ann Arbor, MI.

IProfessor of Pediatrics and Dermatology, Northwestern University Feinberg School of Medicine, and Head, Division of Pediatric Dermatology, Ann \& Robert H. Lurie Children's Hospital of Chicago, Chicago, IL

Publication of this CME article was jointly sponsored by the University of Louisville Continuing Health Sciences Education and Global Academy for Medical Education LLC in affiliation with Skin Disease Education Foundation and is supported by an educational grant from Valeant Pharmaceuticals North America Inc

Lawrence F. Eichenfield, MD, has served as a consultant for Anacor, Bayer, Onset Therapeutics and as speaker and consultant for Valeant. He has also been an investigator and consultant for Galderma, Leo Pharma as well as an investigator for Amgen, Astellas Pharma US, and Stiefel, A GSK Company.

Charles N. Ellis, MD, has served as a consultant for Galderma, Ferndale Laboratories, Medicis, and Novartis.

Anthony J. Mancini, MD, has served as a consultant for Quinnova and Valeant as well as a speaker and consultant for Galderma.

Amy S. Paller, MD, has received grant research support from Astellas.
Successful treatment of atopic dermatitis (AD) depends on Saccurate diagnosis and the development of individualized treatment plans. However, achieving these clinical goals does not ensure the best possible treatment outcome unless compliance is also maximized. Too frequently, less-than-optimal response to therapy or treatment failure can be attributed to adherence issues. For example, Krejci-Manwaring and colleagues ${ }^{1}$ used microprocessor stealth monitoring of medication use to assess adherence in an $\mathrm{AD}$ patient population. These investigators found that overall adherence was only $32 \%$. In another paper from that same study, Feldman and coworkers $^{2}$ described how adherence to topical medication regimens markedly increased during the 8 -week period surrounding the clinic visit, increasing right before and decreasing a few weeks afterward.

Eric L. Simpson, MD, MCR, has served as a consultant, investigator and speaker for Galderma.

The faculty have received an honorarium from Global Academy for Medical Education for their participation in this activity. They acknowledge the editorial assistance of Joanne Still, medical writer, and Global Academy for Medical Education in the development of this continuing medical education journal article. Joanne Still has no relevant financial relationships with any commercial interests.

Address reprint requests to Amy S. Paller, MD, Walter J. Hamlin Professor and Chair, Department of Dermatology, Northwestern University Feinberg School of Medicine, 676 North St. Clair Street, Suite 1600, Chicago, IL 60611, email: APaller@nmff.org 
It is important for clinicians to spend time not only educating patients and parents but also exploring the lifestyles of patients' families to determine which factors might influence medication use and so should be considered in devising a treatment plan. Some areas of discussion should include the time of day when the patient's bath can be done, how often topical emollients can be applied and when this can be done, and the patient's and/or caregivers' preference regarding the type of vehicle in topical medications.

Finally, the concept of written action plans is also critically important. The treatment plan should be discussed, but that information also should be imparted in writing. ${ }^{3}$

Treatment recommendations in AD are based on the current understanding of pathogenesis-ie, the role of skin barrier dysfunction and of the inflammatory processes that drive the condition.

\section{Bathing and Moisturization}

The importance of bathing has long been recognized. Bathing removes some bacteria from the skin, results in some exfoliation, and, importantly, provides hydration. A crucial element of therapy is application after the bath of an appropriate moisturizing agent. Ointments are generally preferred because they reduce transepidermal water loss and, unlike some creams, do not contain preservatives that may sting or burn.

In extremely warm weather, ointments may be too occlusive, and emollient creams are a good alternative in these circumstances. Emollient creams also may be preferred by patients or parents who have strong objections to the greasy feel of ointments. Based on the finding that ceramide tends to be reduced in the skin of patients with $\mathrm{AD}$, some newer emollient agents have been developed that contain this lipid. The amount of ceramide in these products varies. To date, ceramide's mechanism of action and how much ceramide may be needed to affect barrier function have not been clearly established.

Lotions have a high water content and are appropriate for cases in which dryness is not severe or in very warm weather when excess occlusion from ointments or even emollient creams is a concern.

Several medical devices have become available that are primarily designed to improve the skin barrier. These include N-palmitoylethanolamine, a lipid-based ceramide-dominant cream, and MAS063DP. These have largely been tested in patients with mild to moderate eczema and appear to be superior to vehicle. In more severely affected patients, these may be helpful as adjuvant agents. ${ }^{4}$

\section{Anti-inflammatory Modalities}

Topical corticosteroids remain the mainstay of therapy for bringing $\mathrm{AD}$ under control. These are available in a wide variety of strengths, formulations, and vehicles. They range in potency from very-low-strength over-the-counter hydrocortisone to superpotent formulations of various agents ( $\mathrm{Ta}$ ble 1). Class 2 corticosteroids are the strongest usually used in children; stronger topical formulations are sometimes used in adults and may be used selectively for older children.

When used appropriately, topical corticosteroids are associated with few side effects. The risk for side effects-most commonly, atrophy or striae-increases with excessive use of corticosteroids (in duration of use or in frequency of applications) and when potency is too high, particularly when applied to intertriginous areas or the face. Systemic absorption is a rare possibility with the use of low- or mediumstrength corticosteroids, particularly when their application is limited through use of a rotational strategy.

Occasionally, response to a topical corticosteroid may diminish over time in a previous responder, a phenomenon referred to as tachyphylaxis. Reduced or failed response to an agent after initial efficacy suggests the need for a change in the topical regimen, usually to a different corticosteroid of similar potency or to a stronger-potency formulation of the same agent.

However, one of the worst problems associated with topical corticosteroid use is the failure to use the medication, commonly as a result of what has been termed "steroid phobia." Steroid phobia is the fear on the part of patients' parents-and even some clinicians - that topical corticosteroids cause significant local and, possibly, systemic side effects. In fact, in one study, steroid phobia accounted for treatment nonadherence in $36 \%$ of patients or families. ${ }^{5}$ This unwarranted fear has an unfortunate adverse impact on the prescription of and/or adherence to use of what are appropriate first-line medications.

Topical calcineurin inhibitors (TCIs)—specifically, tacrolimus ointment and pimecrolimus cream - have been available for the past decade and are indicated as second-line therapy for intermittent use. However, they commonly are used off-label as first-line therapy for facial dermatitis because, unlike corticosteroids, TCIs have not been associated with ocular problems or cutaneous atrophy.

Tacrolimus ointment, $0.03 \%$, and pimecrolimus cream, $1 \%$, are indicated for use in patients 2 years of age or older. In addition, tacrolimus ointment is available in a $0.1 \%$ strength, indicated for adults and children more than 15 years of age. The indications for tacrolimus were based on early studies suggesting that the $0.03 \%$ and $0.1 \%$ strengths were equally safe and effective. ${ }^{6}$ However, the subsequent widespread clinical experience accumulated with the off-label use of the $0.1 \%$ formulation of tacrolimus in children shows that it is actually more effective than the $0.03 \%$ formulation for pediatric patients. In addition, evidence supports the safe and effective use of the $0.03 \%$ formulation of tacrolimus ointment ${ }^{7}$ and pimecrolimus in children less than 2 years of age, including infants. ${ }^{8,9}$

In 2005, a committee convened by the US Food and Drug Administration (FDA) discussed the possibility of adding a black box warning in the prescribing information for TCIs. The discussions centered on the two areas of concern. The first was that high-dose oral calcineurin inhibitors, given as immunosuppressants in patients who received organ transplants, was associated in a minority of these patients with post-transplant lymphoproliferative disorder, in addition to their increased potential for causing ultraviolet-light-induced nonmelanoma skin cancer. The second area of concern was that administration 
Table 1 Relative Potencies of Topical Corticosteroids

\begin{tabular}{|c|c|c|c|}
\hline Class & Drug & Dosage Form(s) & Strength (\%) \\
\hline \multirow[t]{4}{*}{ I. Very High Potency } & Augmented betamethasone dipropionate & Ointment & 0.05 \\
\hline & Clobetasol propionate & Cream, foam, ointment & 0.05 \\
\hline & Diflorasone diacetate & Ointment & 0.05 \\
\hline & Halobetasol propionate & Cream, ointment & 0.05 \\
\hline \multirow[t]{10}{*}{ II. High Potency } & Amcinonide & Cream, lotion, ointment & 0.1 \\
\hline & Augmented betamethasone dipropionate & Cream & 0.05 \\
\hline & Betamethasone dipropionate & Cream, foam, ointment, solution & 0.05 \\
\hline & Desoximetasone & Cream, ointment & 0.25 \\
\hline & Desoximetasone & Gel & 0.05 \\
\hline & Diflorasone diacetate & Cream & 0.05 \\
\hline & Fluocinonide & Cream, gel, ointment, solution & 0.05 \\
\hline & Halcinonide & Cream, ointment & 0.1 \\
\hline & Mometasone furoate & Ointment & 0.1 \\
\hline & Triamcinolone acetonide & Cream, ointment & 0.5 \\
\hline \multirow[t]{9}{*}{ III-IV. Medium Potency } & Betamethasone valerate & Cream, foam, lotion, ointment & 0.1 \\
\hline & Clocortolone pivalate & Cream & 0.1 \\
\hline & Desoximetasone & Cream & 0.05 \\
\hline & Fluocinolone acetonide & Cream, ointment & 0.025 \\
\hline & Flurandrenolide & Cream, ointment & 0.05 \\
\hline & Fluticasone propionate & Cream & 0.05 \\
\hline & Fluticasone propionate & Ointment & 0.005 \\
\hline & Mometasone furoate & Cream & 0.1 \\
\hline & Triamcinolone acetonide & Cream, ointment & 0.1 \\
\hline \multirow[t]{4}{*}{ V. Lower-Medium Potency } & Hydrocortisone butyrate & Cream, ointment, solution & 0.1 \\
\hline & Hydrocortisone probutate & Cream & 0.1 \\
\hline & Hydrocortisone valerate & Cream, ointment & 0.2 \\
\hline & Prednicarbate & Cream & 0.1 \\
\hline \multirow[t]{3}{*}{ VI. Low Potency } & Alclometasone dipropionate & Cream, ointment & 0.05 \\
\hline & Desonide & Cream, gel, foam, ointment & 0.05 \\
\hline & Fluocinolone acetonide & Cream, solution & 0.01 \\
\hline \multirow[t]{3}{*}{ VII. Lowest Potency } & Dexamethasone & Cream & 0.1 \\
\hline & Hydrocortisone & Cream, lotion, ointment, solution & $0.25,0.5,1$ \\
\hline & Hydrocortisone acetate & Cream, ointment & $0.5-1$ \\
\hline
\end{tabular}

Source: Paller AS, Mancini AJ. Eczematous eruptions in childhood. In: Paller AS, Mancini AJ. Hurwitz Clinical Pediatric Dermatology. St Louis, MO: Elsevier Inc; 2011; chapter 3, p 49. Reprinted with permission.

of very high doses of oral calcineurin inhibitors was associated with lymphoma in some animal studies.

The FDA committee recommended inclusion of a black box warning based on the theoretical possibility of malignancy, which was instituted in 2006 and remains in effect to date. However, in more than a decade following their introduction, no evidence has emerged to indicate that TCIs increase the risk for these problems in individuals who use them for AD. In fact, one case-controlled study of 5,000 adults with dermatitis showed that the $26 \%$ of subjects who had been exposed to TCIs had a decreased risk for nonmelanoma skin cancer, with the odds ratio for this association decreasing as the number of tubes used or the potency of the TCI increased. ${ }^{10}$

Arellano and colleagues ${ }^{11}$ examined the risk of lymphoma in $\mathrm{AD}$ in two studies. A case-controlled study of more than 2,700 cases from the UK database of lymphoma among 3.5 million persons and about 11,000 matched controls demonstrated an increased risk of lymphoma in patients with AD in general, particularly in more severe cases. A correlation was shown between lymphoma and high-potency topical corticosteroids, but not TCIs, in the AD population. The other study by these investigators was a nested case-controlled study of close to 300,000 patients with AD, approximately 59\% of them children. ${ }^{12}$ Three hundred cases of lymphoma were identified and, again, were correlated with disease severity but not with the use of TCIs.

Moreover, no signal of concern has emerged in data relating specifically to children. By 2011, an ongoing 10-year safety study of tacrolimus had enrolled more than 6,000 children, and-based on Surveillance, Epidemiology, and End Results (SEER) data-no increased incidence of lymphoma or nonmelanoma skin cancer had been noted. Serious adverse events-primarily asthma-were reported in less than 5\% of patients. ${ }^{13}$

\section{Rotational and Intermittent Therapy Strategies}

The concept of rotation therapy emerged with the increased understanding of and attention focused on the skin barrier in AD. Studies of the effects on skin barrier function of topical 
corticosteroids and TCIs have demonstrated that corticosteroids compromise skin barrier function with long-term therapy and that this compromise actually may happen fairly quickly_within as little as 2 to 3 days with some of the higher-potency agents. ${ }^{14-17}$ In contrast, repair of some of the corticosteroid-induced barrier has been seen with TCIs. ${ }^{16}$

Taking advantage of these mechanisms, rotational therapy involves the initial use of a medium-strength topical corticosteroid for AD flares, then switching to a TCI (rather than a lower-strength corticosteroid) when the flare is under control. ${ }^{18}$

To minimize long-term, chronic application of corticosteroids - and the risk for chronic impairment of barrier function-intermittent therapy should be considered as maintenance treatment. Hanifin and colleagues ${ }^{19}$ tested this strategy with twice-weekly applications of fluticasone cream as maintenance and found it to be effective. This concept of "dialing down" was subsequently tested using tacrolimus ointment to decrease corticosteroid use for maintenance. Several studies have demonstrated that, once a flare is under control with corticosteroids and the skin in that area is clear or almost clear, the application of tacrolimus two to three times weekly provides an effective means of extending the corticosteroidfree periods between recurrent flares. ${ }^{18,20,21}$ A maintenance schedule of twice-weekly application of TCIs to clear or almost-clear areas is currently indicated in Europe. ${ }^{22}$

\section{Preventing and Managing Infections}

Infection in patients with $\mathrm{AD}$, heralded by crusting or pustules, is treated with systemic antibiotics; topical antibiotics have been tried but have not proved to be effective. Interestingly, decades of experience with certain systemic agentsfor example, cephalexin - has shown that antimicrobial therapy often results in dramatic improvement of inflammation as well as control of an infection. To date, however, no good clinical trial has been published that supports this clinical observation.

It is not uncommon for patients to experience an AD flare within a few days to a few weeks following completion of the oral antibiotic regimen. The timing of this flare tends to correlate with the severity of a patient's disease and reinfection. Presumably, the flare and reinfection tendency relates to Staphylococcus aureus overgrowth, and several groups currently are investigating ways to prolong improvement following oral antibiotic therapy.

One relatively new technique that has become the standard of care in the United States for infection-prone patients with AD is the dilute bleach bath-that is, adding sodium hypochlorite (chlorine bleach) to bath water. Huang and colleagues ${ }^{20}$ conducted a study of 31 children with moderate to severe $\mathrm{AD}$ and skin infections, in which decreasing $S$. aureus colonization in the nose and on the skin was associated with a decrease in severity of $\mathrm{AD}$. In this study, nose and skin cultures were obtained prior to initiation of oral cephalexin treatment. Patients were then randomized to receive either bleach in their bath water plus a monthly course of intranasal mupirocin or no bleach in their bath water and a placebo for intranasal administration. Family members of the bleach bath group also received intranasal mupirocin; family members of the no bleach group were given intranasal placebo.

With twice-weekly bathing, both eczema severity and the affected body surface area (BSA) had dramatically decreased in the bleach bath/intranasal mupirocin group, reaching statistical significance by 1 month ( $p=0.02$ for Eczema Area and Severity Index [EASI]; $p=0.05$ for BSA) and even greater significance by the end of the study at 3 months ( $p=0.004$ for both EASI and BSA). A post hoc analysis showed that these differences were evident only on the limbs and trunk-the areas of the body submerged in the bath; no differences were noted between the two groups in $\mathrm{AD}$ sites on the head and neck, which were not submerged. Cultures performed throughout the study demonstrated the persistence of $S$. aureus colonization; thus, the number of organism was suppressed, but $S$. aureus was not eliminated.

Dilute bleach baths must be continued as a maintenance treatment for $S$. aureus overgrowth to remain suppressed. The current recommendation for the concentration of bleach in the bath is $0.005 \%$. The typical concentration of sodium hypochlorite in common household bleach (used in laundry, for example) is $6 \%$, so $1 / 4$ cup of bleach added to a half-filled, standard, 40-gallon bathtub (or $1 / 2$ cup added to a full bathtub) will yield the proper concentration. If a baby bathing basin is used, the proper concentration can be achieved by adding $3 \mathrm{cc}$ of household bleach to each gallon of water.

Other steps should be considered to minimize $S$. aureus exposure in patients with $\mathrm{AD}$, particularly in those who have already experienced one or more infections. One possible source of $S$. aureus contamination that has been discovered in recent years is unpreserved topical agents (prescription and nonprescription) used in $\mathrm{AD}$. In one study, Carr and colleagues ${ }^{23}$ cultured bacteria from the rims, nozzles, and containers of ointments, emollients, and topical corticosteroid medications. About half of the containers were contaminated by bacteria, and, of these, S. aureus was cultured in half. Keeping in mind the ubiquitous nature of $S$. aureus, clinicians should consider advising parents to keep moisturizers and topical medications in the refrigerator (warming them by floating them in the bathtub prior to after-bath application). Parents also should be instructed to use a tongue blade or a clean spoon to remove medications and moisturizers from their containers, thereby avoiding hand contamination of the remaining product.

Furthermore, in cases in which infections are recurrent, it may be helpful to have family members use mupirocin intranasally and also to use mupirocin ointment on the hands. In one study of bacterial cultures from skin and nares, $65 \%$ of parents also showed S. aureus colonization, and in $84 \%$ of these isolates, the $S$. aureus characteristics were shared with those of their children with AD. ${ }^{24}$ In the future, other measures such as the use of alternative antiseptic products (cur- 
rently in development or being studied) or antibacterial clothing may help reduce recurrent infections in susceptible patients with $\mathrm{AD}$.

\section{Refractory AD}

In patients who do not respond as expected to appropriate management and in whom tachyphylaxis has been ruled out by changing topical medications, the possibility of an incorrect diagnosis must be considered. Many conditions mimic AD and range from genetic disorders such as Netherton syndrome, hyper-immunoglobulin E syndrome, and Wiskott-Aldrich syndrome to conditions like allergic contact dermatitis, secondarily eczematized scabies, and tinea incognito,

In addition, studies have shown that contact dermatitis can coexist with AD. ${ }^{25}$ Beattie and colleagues ${ }^{26}$ showed that $6 \%$ to $22 \%$ of patients with $\mathrm{AD}$ had a positive patch test beyond nickel, and half of them were sensitive to agents in their emollient. Thus, it is important to be mindful that additives used in emollients, skin cleansers, and even topical corticosteroids can be contact sensitizers.

After considering and ruling out these alternative explanations for failure to respond adequately, more aggressive approaches can be considered. One of these is hospitalization, during which patients can receive careful monitoring and intensive attention, including ready access to consultants. Hospitalization has the added advantage of providing respite for the family, as well as a focused opportunity for them to receive further education about the proper use of medications. Of course, hospitalization itself presents certain risks, including that of exposure to bacterial infection, so the duration of the stay should be minimized.

Systemic intervention is an option in some patients, and the patient's and family's quality of life should be included as factors when considering such a decision. The process must include a discussion with the family concerning the risks for infection and neoplasia, particularly lymphoma.

No large comparative trials have been published, and no detailed treatment guidelines currently exist on the use of systemic immunosuppressants for AD in children. Some case series have been published. ${ }^{27-32}$ These studies all show the potential efficacy and limited toxicity of these immunosuppressants when used for limited periods and with careful monitoring (as described below).

In general, topical anti-inflammatories should be continued during initiation of systemic immunosuppressant therapy, and these topicals subsequently phased out, if possible. If topical therapy is continued, a rotational strategy should be considered. Side effects from appropriately used topical agents are unusual, even with concomitant use of systemic immunosuppressants.

Nonsteroidal immunosuppressants are preferred because of the potential side effects associated with the use of systemic corticosteroids. In addition, rebound flare of $\mathrm{AD}$ is a common problem in children when systemic corticosteroids are discontinued.

More commonly, cyclosporine, azathioprine, mycopheno- late mofetil, and methotrexate are used. Among these immunosuppressants, cyclosporine has the most rapid onset of action. A meta-analysis that included 15 studies showed that cyclosporine administration was associated with a decrease in disease severity by $55 \%$ at 6 to 8 weeks. ${ }^{27}$ In addition, open-label studies have been done in children, specifically, using $5 \mathrm{mg} / \mathrm{kg} /$ day, adjusted as needed for therapeutic effect. This regimen has yielded reductions in severity of scores ranging from $50 \%$ to $60 \%$ after 6 to 8 weeks of treatment. 28,29 Continuous administration of cyclosporine, tapered to the lowest therapeutic level, seems to yield approximately the same clinical results as administration of intermittent 12 week courses of therapy. ${ }^{30}$ The effective dose should be maintained for a few months and then tapered gradually, with exposure to cyclosporine limited to 1 year.

Azathioprine has received greater attention recently $y^{30,31}$ and is the treatment of choice in the United Kingdom. In a study of 48 children, Murphy and Atherton ${ }^{32}$ found an excellent response in about $60 \%$ of children with severe $\mathrm{AD}$ at 3 months. Azathioprine has a delayed onset of efficacy of 4 to 6 weeks, so some clinicians begin concurrent treatment with azathioprine and a corticosteroid, tapering off the corticosteroid starting 1 month later. In general, the optimum dosage is 2.5 to $3.5 \mathrm{mg} / \mathrm{kg} / \mathrm{day}$ of azathioprine; however, if an intermediate level of the erythrocyte thiopurine methyltransferase (TPMT) enzyme is obtained (see the discussion of monitoring, below), that dosage can be adjusted downward to $1 \mathrm{mg} / \mathrm{kg} /$ day. An effective dose should be maintained for about 3 months, then tapered gradually; azathioprine can be used for 2 years before transitioning to an alternative therapy.

Another option is mycophenolate mofetil, which is among the least toxic (although costlier) systemic immunosuppressants for AD. As with azathioprine, mycophenolate mofetil's onset of efficacy is delayed for 4 to 8 weeks. The maximal effect is seen at 8 to 12 weeks after initiation, so, here again, concurrent administration of corticosteroid at the start of therapy, followed by tapering and then discontinuation, is advisable. In a study by Heller et al, ${ }^{33} 58 \%$ of patients showed greater than $90 \%$ improvement, and $93 \%$ of patients showed greater than $60 \%$ improvement. In children, a dosage of 40 to $50 \mathrm{mg} / \mathrm{kg} /$ day (or 600 to $1,200 \mathrm{mg} / \mathrm{m}^{2}$ ) is the usual dosage. For adolescents, a dosage range of 30 to $40 \mathrm{mg} / \mathrm{kg} /$ day will yield a maximum level of $3 \mathrm{~g} / \mathrm{day}$. The use of mycophenolate mofetil should be limited to 2 years.

Finally, methotrexate has been found to be helpful, particularly once a flare has subsided. In fact, methotrexate probably is most suitable for maintenance in severe $\mathrm{AD}$. For this use, the dosage is 0.5 to $0.6 \mathrm{mg} / \mathrm{kg} /$ week, with a maximum of $20 \mathrm{mg}$. This can be administered in a single dose each week, although some clinicians have found that efficacy is greater if the dosage is divided over several consecutive days. Concomitant administration of folic acid is important during methotrexate therapy. No studies of methotrexate have been done in children with $\mathrm{AD}$. In a study of adults, Weatherhead et $\mathrm{al}^{34}$ demonstrated that 
Table 2 Clinical and Laboratory Monitoring During Systemic Immunosuppressant Therapy

\begin{tabular}{|c|c|c|c|c|}
\hline \multirow[b]{2}{*}{ Test } & \multicolumn{4}{|c|}{ Medication } \\
\hline & Azathioprine & Cyclosporine & Methotrexate & $\begin{array}{l}\text { Mycophenolate } \\
\text { mofetil }\end{array}$ \\
\hline Blood pressure & 一 & $\begin{array}{l}\text { Monitor weekly for } 1 \text { month, } \\
\text { then monthly thereafter }\end{array}$ & - & - \\
\hline CBC & $\begin{array}{l}\text { Baseline, then every } 2 \\
\text { weeks for } 1 \text { month, } \\
\text { then monthly for } 2 \\
\text { months, then every } \\
2 \text { months for } \\
\text { duration of therapy }\end{array}$ & $\begin{array}{l}\text { Baseline, then monthly for } \\
\text { the first few months, then } \\
\text { every other month for } \\
\text { duration of therapy }\end{array}$ & $\begin{array}{l}\text { Baseline, then monthly } \\
\text { for } 2 \text { months, then } \\
\text { every } 3 \text { months for } \\
\text { duration of therapy }\end{array}$ & $\begin{array}{l}\text { Baseline, then monthly } \\
\text { for } 2 \text { months, then } \\
\text { every } 3 \text { months for } \\
\text { duration of therapy }\end{array}$ \\
\hline Liver function tests & $\begin{array}{l}\text { Baseline, then every } 2 \\
\text { weeks for } 1 \text { month, } \\
\text { then monthly for } 2 \\
\text { months, then every } \\
2 \text { months for } \\
\text { duration of therapy }\end{array}$ & $\begin{array}{l}\text { Baseline, then monthly for } \\
\text { the first few months, then } \\
\text { every other month for } \\
\text { duration of therapy }\end{array}$ & $\begin{array}{l}\text { Baseline, then monthly } \\
\text { for } 2 \text { months, then } \\
\text { every } 3 \text { months for } \\
\text { duration of therapy }\end{array}$ & $\begin{array}{l}\text { Baseline, then monthly } \\
\text { for } 2 \text { months, then } \\
\text { every } 3 \text { months for } \\
\text { duration of therapy }\end{array}$ \\
\hline BUN level & - & $\begin{array}{l}\text { Baseline, then monthly for } \\
\text { the first few months, then } \\
\text { every other month for } \\
\text { duration of therapy }\end{array}$ & - & - \\
\hline Creatinine level & - & $\begin{array}{l}\text { Baseline, then monthly for } \\
\text { the first few months, then } \\
\text { every other month for } \\
\text { duration of therapy }\end{array}$ & - & - \\
\hline $\begin{array}{l}\text { Erythrocyte TPMT } \\
\text { enzyme }\end{array}$ & $\begin{array}{l}\text { Baseline, then every } 2 \\
\text { weeks for } 1 \text { month, } \\
\text { then monthly for } 2 \\
\text { months, then every } \\
2 \text { months for } \\
\text { duration of therapy }\end{array}$ & - & - & - \\
\hline
\end{tabular}

BUN, blood-urea-nitrogen; CBC, complete blood count; TPMT, erythrocyte thiopurine methyltransferase.

methotrexate resulted in a decrease in severity of $52 \%$ from baseline over a 24 -week period.

Clinical and laboratory monitoring is crucial during treatment with systemic immunosuppressants (Table 2). Among the four agents discussed here, cyclosporine is associated with the greatest number of potential side effects. Neoplasia is a potential long-term risk. Shorter-term, increased risks for infection, renal and hepatic toxicity, and hypertrichosis are associated with cyclosporine. During treatment, blood pressure should be monitored weekly for 1 month, then monthly thereafter. Baseline laboratory tests should include complete blood count $(\mathrm{CBC})$, liver function tests, and blood-urea-nitrogen and creatinine levels; these tests should be repeated monthly for at least the first few months, then every other month thereafter.

With the use of azathioprine, a baseline level of erythrocyte TPMT should be obtained; inadequate levels of this enzyme are associated with the greatest risk for myelosuppression. Baseline CBC and liver function tests also are important. These studies should be repeated every 2 weeks for 1 month, then monthly for 2 months, and every 2 months thereafter for the duration of treatment.

For mycophenolate mofetil and methotrexate therapy, monitoring should include baseline $\mathrm{CBC}$ and liver function tests, repeated monthly for 2 months, then every 3 months for the duration of treatment.

An alternative to systemic immunosuppressive treatment is phototherapy, preferably with narrowband ultraviolet B (UVB) light. Clayton and colleagues ${ }^{35}$ presented a retrospective review of 50 children with severe AD who were treated with at least 10 exposures to narrowband UVB. Complete clearance was seen in $40 \%$ of patients, with good improvement in 23\% and moderate improvement in 26\%; the median length of remission was 3 months.

There are several disadvantages to using narrowband UVB in children. First, it requires cooperation by the child, either alone or with a parent in the phototherapy booth. Second, the time commitment required for treatments is often difficult to secure, conflicting with parents' work schedules and children's school and recreational activities. Third, the potential risks for skin cancer and premature aging are unknown at this time.

\section{Adjuvant Therapy}

Wet wraps are a traditional method for decreasing inflammation and pruritus and increasing comfort, particularly during an AD flare. Some centers, such as the Mayo Clinic, have used 
inpatient wet-wrap therapy for rapid control of pediatric AD. ${ }^{36}$ The method has gained renewed and more widespread interest in recent years, and several authors have provided evidence of efficacy and guidelines for use in AD. . $^{37-38}$

This technique is simple enough to use at home. Following a bath and application of medications and moisturizers, the affected areas are wrapped in wet gauze and topped by a dry layer. If the $\mathrm{AD}$ is widespread, it is more convenient (and cost-effective) to dress the child in wet pajamas, followed by warmed, dry towels or blankets. Wet wrapping used at night can decrease pruritus and help children sleep. This technique usually is more successful in infants and toddlers; older children may refuse to leave the wet wraps in place or may refuse to allow the treatment at all. One needs to keep in mind that when using a topical corticosteroid, wrapping will increase the potential absorption.

Antihistamines are not particularly useful for decreasing pruritus associated with $\mathrm{AD}$, but can be very helpful to promote sleep when used at sedating dosages-for example, hydroxyzine given at $1 \mathrm{mg} / \mathrm{kg} / \mathrm{day}$.

\section{Conclusion}

A number of effective and safe agents are available to manage $\mathrm{AD}$ flares and extend periods of remission between flares. However, no single regimen will work for all patients with AD. Treatment strategies must be individualized and modified over time as patient needs require and, in the case of children, as caregiver adherence permits. Sufficient time must be spent educating patients and parents about the risks and benefits of therapy as well as allaying unfounded fears about medication side effects, particularly regarding topical corticosteroids.

\section{References}

1. Krejci-Manwaring J, Tusa MG, Carroll C, et al: Stealth monitoring of adherence to topical medication: Adherence is very poor in children with atopic dermatitis. J Am Acad Dermatol 56:211-216, 2007

2. Feldman SR, Camacho FT, Krejci-Manwaring J, et al: Adherence to topical therapy increases around the time of office visits. J Am Acad Dermatol 57:81-83, 2007

3. Chisolm SS, Taylor SL, Balkrishnan R, et al: Written action plans: Potential for improving outcomes in children with atopic dermatitis. J Am Acad Dermatol 59:677-683, 2008

4. Draelos ZD: New treatments for restoring impaired epidermal barrier permeability: Skin barrier repair creams. Clin Dermatol 30:345-348, 2012

5. Aubert-Wastiaux H, Moret L, Le Rhun A, et al: Topical corticosteroid phobia in atopic dermatitis: A study of its nature, origins and frequency. Br J Dermatol 165:808-814, 2011

6. Paller A, Eichenfield LF, Leung DYM, et al: A 12-week study of tacrolimus ointment for the treatment of atopic dermatitis in pediatric patients. J Am Acad Dermatol 44:S47-S57, 2001

7. Mandelin JM, Rubins A, Remitz A, et al: Long-term efficacy and tolerability of tacrolimus $0.03 \%$ ointment in infants: A two-year open-label study. Int J Dermatol 51:104-110, 2012

8. Bishop M, Vukovic-Wysocki I, Qaqundah P, et al: A 5-year randomized study to investigate the safety of pimecrolimus cream 1\% in the treatment of mild-to-moderate atopic dermatitis in infants: Immunologic parameters. J Am Acad Dermatol 64:AB56, 2011 (2 suppl 1)

9. Eichenfield LF, Beck L: Elidel (pimecrolimus) cream 1\%: A nonsteroi- dal topical agent for the treatment of atopic dermatitis. J Allergy Clin Immunol 111:1153-1168, 2003.

10. Margolis DJ, Hoffstad O, Bilker W: Lack of association between exposure to topical calcineurin inhibitors and skin cancer in adults. Dermatology 214:289-295, 2007

11. Arellano FM, Arana A, Wentworth CE, et al: Lymphoma among patients with atopic dermatitis and/or treated with topical immunosuppressants in the United Kingdom. J Allergy Clin Immunol 123:11111116,2009

12. Arellano FM, Wentworth CE, Arana A, et al: Risk of lymphoma following exposure to calcineurin inhibitors and topical steroids in patients with atopic dermatitis. J Invest Dermatol 127:808-816, 2007

13. Ohtsuki M, Ohara H, Santos V, et al: Safety profiles of two large cohort studies of tacrolimus ointment for the treatment of atopic dermatitis: A prospective pediatric longitudinal evaluation study (APPLES) and Japanese long-term safety study (J-LSS). Poster presented at: 22nd World Congress of Dermatology; May 24-29, 2011; Seoul, Korea.

14. Kao JS, Fluhr JW, Man MQ, et al: Short-term glucocorticoid treatment compromises both permeability barrier homeostasis and stratum corneum integrity: Inhibition of epidermal lipid synthesis accounts for functional abnormalities. J Invest Dermatol 120:456-464, 2003

15. Cork MJ, Varghese J, Hadcraft J, et al: Differences in the effect of topical corticosteroids and calcineurin inhibitors on the skin barrier: Implications for therapy. J Invest Dermatol 127:S45, 2007

16. Cork MJ, Varghese J, Sultan A, et al: Therapeutic implications of the differential effects of topical corticosteroids and calcineurin inhibitors on the skin barrier. Poster presented at: 5 th George Rajka International Symposium on Atopic Dermatitis (ISAD); May 11-13, 2008; Kyoto, Japan.

17. Cork MJ, Danby SG, Vasilopoulos Y, et al: Epidermal barrier dysfunction in atopic dermatitis. J Invest Dermatol 129:1892-1908, 2009

18. Paller AS, Eichenfield LF, Kirsner RS, et al: Three times weekly tacrolimus ointment reduces relapse in stabilized atopic dermatitis: A new paradigm for use. Pediatrics 122:e1210-e1218, 2008

19. Hanifin J, Gupta AK, Rajagopalan R: Intermittent dosing of fluticasone propionate cream for reducing the risk of relapse in atopic dermatitis patients. Br J Dermatol 147:528-537, 2002

20. Huang JT, Abrams M, Tlougan B, et al: Treatment of Staphylococcus aureus colonization in atopic dermatitis decreases disease severity. Pediatrics 123:e808-e814, 2009

21. Breneman D, Fleischer AB Jr, Abramovits W, et al: Intermittent therapy for flare prevention and long-term disease control in stabilized atopic dermatitis: A randomized comparison of 3-times-weekly applications of tacrolimus ointment versus vehicle. J Am Acad Dermatol 58:990999, 2008

22. Thaci D, Chambers C, Sidhu M, et al: Twice-weekly treatment with tacrolimus $0.03 \%$ ointment in children with atopic dermatitis: Clinical efficacy and economic impact over 12 months. J Eur Acad Dermatol Venereol 24:1040-1046, 2010

23. Carr J, Akram M, Sultan A, et al: Contamination of emollient creams and ointments with Staphylococcus aureus in children with atopic dermatitis. Dermatitis 19:282, 2008

24. Bonness S, Szekat C, Novak N, et al: Pulsed-field gel electrophoresis of Staphylococcus aureus isolates from atopic patients revealing presence of similar strains in isolates from children and their parents. J Clin Microbiol 46:456-461, 2008

25. Mailhol C, Lauwers-Cances V, Rancé F, et al: Prevalence and risk factors for allergic contact dermatitis to topical treatment in atopic dermatitis: A study in 641 children. Allergy 64:801-806, 2009

26. Beattie PE, Green C, Lowe G, et al: Which children should we patch test? Clin Exp Dermatol 32:6-11, 2007

27. Schmitt J, Schmitt N, Meurer M: Cyclosporin in the treatment of patients with atopic eczema: A systematic review and meta-analysis. J Eur Acad Dermatol Venereol 21:606-619, 2007

28. Harper JI, Ahmed I, Barclay G, et al: Cyclosporin for severe childhood atopic dermatitis: Short course versus continuous therapy. Br J Dermatol 142:52-58, 2000

29. Harper JI, Berth-Jones J, Camp RD, et al: Cyclosporin for atopic dermatitis in children. Dermatology 203:3-6, 2001 
30. Hon KL, Ching GK, Leung TF, et al: Efficacy and tolerability at 3 and 6 months following use of azathioprine for recalcitrant atopic dermatitis in children and young adults. J Dermatolog Treat 20:141-145, 2009

31. Waxweiler WT, Agans R, Morrell DS: Systemic treatment of pediatric atopic dermatitis with azathioprine and mycophenolate mofetil. Pediatr Dermatol 28:689-694, 2011

32. Murphy LA, Atherton D: A retrospective evaluation of azathioprine in severe childhood atopic eczema, using thiopurine methyltransferase levels to exclude patients at high risk of myelosuppression. Br J Dermatol 147:308-315, 2002

33. Heller M, Shin HT, Orlow SJ, et al: Mycophenolate mofetil for severe childhood atopic dermatitis: Experience in 14 patients. Br J Dermatol 157:127-132, 2007

34. Weatherhead SC, Wahie S, Reynolds NJ, et al: An open-label, dose- ranging study of methotrexate for moderate-to-severe adult atopic eczema. Br J Dermatol 156:346-351, 2007

35. Clayton TH, Clark SM, Turner D, et al: The treatment of severe atopic dermatitis in childhood with narrowband ultraviolet B phototherapy. Clin Exp Dermatol 32:28-33, 2007

36. Dabade TS, Davis DM, Wetter DA, et al: Wet dressing therapy in conjunction with topical corticosteroids is effective for rapid control of severe pediatric atopic dermatitis: Experience with 218 patients over 30 years at Mayo Clinic. J Am Acad Dermatol 67:100-106, 2012

37. Devillers AC, Oranje AP: Wet-wrap treatment in children with atopic dermatitis: A practical guideline. Pediatr Dermatol 29:24-27, 2012

38. Song T: The efficacy of wet wrap treatment in children with atopic dermatitis. J Allergy Clin Immunol 127:AB36, 2011(2 suppl) 